\title{
25-Hydroxyvitamin D Is Associated with Kidney Function: The Dong-gu Study
}

\author{
Seong-Woo CHOI ${ }^{1}$, Sun-Seog KWEON ${ }^{2,3}$, Young-Hoon $\mathrm{LEE}^{4}$, So-Yeon RYu ${ }^{1}$, \\ Hae-Sung NAM ${ }^{5}$, Kyeong-Soo PARK ${ }^{6}$, Sun A KIM ${ }^{2}$ and Min-Ho SHIN ${ }^{2,7, *}$ \\ ${ }^{1}$ Department of Preventive Medicine, Chosun University Medical School, \\ 309, Pilmun-daero, Dong-gu, Gwangju 61452, Republic of Korea \\ ${ }^{2}$ Department of Preventive Medicine, Chonnam National University Medical School, \\ 264, Seoyang-ro, Hwasun 58128, Republic of Korea \\ 3 Jeonnam Regional Cancer Center, Chonnam National University Hwasun Hospital, \\ 264, Seoyang-ro, Hwasun 58128, Republic of Korea \\ ${ }^{4}$ Department of Preventive Medicine \& Institute of Wonkwang Medical Science, Wonkwang \\ University School of Medicine, 460, Iksandae-ro, Iksan 54538, Republic of Korea \\ ${ }^{5}$ Department of Preventive Medicine, Chungnam National University Medical School, \\ 266, Munhwa-ro, Jung-gu, Daejeon 35015, Republic of Korea \\ ${ }^{6}$ Department of Preventive Medicine, Seonam University College of Medicine, \\ 439, Chunhyang-ro, Namwon 55724, Republic of Korea \\ ${ }^{7}$ Center for Creative Biomedical Scientists, Chonnam National University, \\ 77 Yongbong-ro, Buk-gu, Gwangju 61186, Republic of Korea
}

(Received February 17, 2018)

\begin{abstract}
Summary Although the kidneys play a leading part in the biosynthesis of vitamin D, there is no consensus regarding the relationship of the vitamin D concentration with kidney function. Thus, we aimed to estimate the correlation among 25-hydroxyvitamin D (25(OH)D), estimated glomerular filtration rate (eGFR), and albumin/creatinine ratio (ACR) in participants aged $\geq 50 \mathrm{y}$ in Korea. This study consisted of 9,166 people who participated in a basic survey of the Dong-gu Study. Following an overnight fast, the blood and urine sample were assessed. The serum 25(OH)D, eGFR, ACR of each subject were measured. When adjusting for covariates and log-transformed ACR (Model III), the lower eGFR value was significantly associated with increasing 25(OH)D levels (<10.0: 71.5 [70.5-72.4]; 10.0-14.9: 70.0 [69.5-70.4]; 15.0-19.9: 68.7 [68.3-69.2]; $\geq 20.0: 67.4$ [66.8-67.9] $\mathrm{mL} / \mathrm{min} / 1.73 \mathrm{~m}^{2}$, $p<0.001$ ). When adjusted for the same covariates and log-transformed eGFR (Model III), the lower ACR value was significantly associated with increasing 25(OH)D levels $(<10.0$ : 57.4 [48.0-66.9]; 10.0-14.9: 40.8 [36.5-45.2]; 15.0-19.9: 34.0 [29.5-38.5]; $\geq 20.0$ : $34.3[28.8-39.8] \mu \mathrm{g} / \mathrm{mg}$ creatinine, $p<0.001)$. In conclusion, the mean values of eGFR were significantly decreased with increasing 25(OH)D levels independent of ACR. In additon, the mean values of ACR were significantly decreased with increasing 25(OH)D levels independent of eGFR in participants aged $\geq 50 \mathrm{y}$ in Korea.
\end{abstract}

Key Words glomerular filtration rate, albuminuria, 25-hydroxyvitamin D, kidney function

Chronic kidney disease (CKD), which encompasses all degrees of impaired renal function, affects approximately $17 \%$ of the U.S. general population (1). A decreased glomerular filtration rate (GFR) is a major cause of cardiovascular disease (CVD) (2) and reduced renal function is associated with the increase of all-cause mortality and CVD events in high-risk patients (3), as well as in the general population (4). Albuminuria is known to a predictor of the mortality and morbidity of CVD, endstage kidney disease, and CKD progression $(5,6)$. Thus, the detection and treatment of risk factors associated with decreased GFR and albuminuria may prevent CKD progression and reduce the risk of CVD (7).

Vitamin D plays a vital part in maintaining serum

*To whom correspondence should be addressed.

E-mail:mhshinx@paran.com calcium level (8). Not less than $80 \%$ of vitamin D is synthesized from cholesterol by ultraviolet radiation in the skin, while the remaining $10-20 \%$ is obtained from diet; fish oil, dairy foods and various supplements (9). First, ergocalciferol (vitamin $\mathrm{D}_{2}$ ) and cholecalciferol (vitamin $\mathrm{D}_{3}$ ) are ingested through the diet or ultraviolet radiation. These two vitamin $\mathrm{D}$ metabolites are hydroxylated within the liver to calcifediol $(25(\mathrm{OH}) \mathrm{D})$ and after that, it is hydroxylated within the kidneys to the biologically active metabolite, calcitriol $\left(1,25(\mathrm{OH})_{2} \mathrm{D}\right)(10)$. Thus, the kidney has a critical role in the biosynthesis of $1,25(\mathrm{OH})_{2} \mathrm{D}$ even though there is no concordance regarding the relationship of the vitamin D concentrations with kidney function. Some studies demonstrated positive relationships between the $25(\mathrm{OH}) \mathrm{D}$ and the estimated GFR (eGFR) $(11,12)$; others reported inverse associations $(13,14)$; still others presented no associa- 
tion $(15,16)$. These discrepancies may be due to differences in race, age, latitude and CKD status of the subjects.

South Korea has recently become known as a country of vitamin D deficiency $(17,18)$. However, because there have been only a few vitamin D related studies within the Korean population, whether the low vitamin D levels are correlated with eGFR and albumin/ creatinine ratio (ACR) in Korean population needs to be verified. Therefore, we aimed to evaluate the correlation among 25(OH)D, eGFR, and ACR in a population aged $\geq 50$ y in Korea .

\section{MATERIALS AND METHODS}

Subjects. We conducted this study as a basic survey of the Dong-gu Study. A previous publication has shown the detailed information (19). By using National resident registration data in the Gwangju Metropolitan area from 2007 to 2010, we selected 34,040 potential subjects who were over $50 \mathrm{y}$ old and lived in the district of Dong-gu. We contacted the eligible residents by telephone or e-mail and encouraged them to visit the Donggu health center to participate this survey; ultimately, 9,260 subjects were signed up in the Dong-gu Study from 2007 to 2010 and the response rate was $27.2 \%$. After excluding 94 participants who were lacking vital data $(n=91)$, such as $25(\mathrm{OH}) \mathrm{D}$ or serum creatinine levels, and/or had a high urine ACR $\geq 3,000 \mathrm{mg} / \mathrm{g}(n=3)$, which is indicative of nephrotic-range albuminuria or altered vitamin D metabolism (20), we analyzed a total of 9,166 subjects (men: 3,668 and women: 5,498) in this study.

Data collection. The trained staff interviewed the subjects using a questionnaire that included items on smoking, alcohol intake, physical activity, history of diabetes and hypertension medication, and multi-vitamin intake. The smoking status was assessed by self-report; if the participant had smoked more than 100 cigarettes in his whole life, he was counted as a smoker. Alcohol intake was assessed as positive if the participant drank alcohol in last month and physical activity was counted if a subject worked out regularly.

The trained researchers measured the weight, height, and waist circumference of the subjects in units of $0.1 \mathrm{~kg}$ or $0.1 \mathrm{~cm}$ while the participant was wearing light clothes and socks. The waist circumference was measured at expiration by placing a flexible tape parallel to the floor at the midpoint between the iliac crest and the lowest rib.

Following an overnight fast, the venous blood sample was taken from an antecubital vein of the participant. After the separation of serum on site, the serum was frozen at $-70^{\circ} \mathrm{C}$ until further measure. By using enzymatic methods, the concentrations of serum lipid profile such as high-density lipoprotein cholesterol (HDL-C), triglyceride, total cholesterol (TC) were measured with a Hitachi-7600 automatic biological analyzer (Hitachi Ltd., Tokyo, Japan).

Kidney function. GFR was estimated by the equation of the Chronic Kidney Disease Epidemiology Collabora- tion (CKD-EPI) (21);

$$
\begin{aligned}
\mathrm{eGFR}_{\text {CKD-EPI }}= & 141 \times \min \left(\frac{\mathrm{Scr}}{\kappa}, 1\right)^{\alpha} \times \max \left(\frac{\mathrm{Scr}}{\kappa}, 1\right)^{-1.209} \\
& \times 0.993^{\mathrm{age}} \times 1.018(\text { if female })
\end{aligned}
$$

Urine creatinine was measured using the Jaffé reaction (22) and urine albumin was measured via turbidimetric immunoassay with a Hitachi-7600 automatic biological analyzer (Hitachi Ltd.). ACR was calculated as the concentration of urine albumin $(\mu \mathrm{g})$ divided by the concentration of urine creatinine $(\mathrm{mg})$ and albuminuria was defined according to the ACR level.

Measurement of serum concentrations of parathyroid hormone (PTH) and 25(OH)D. Serum PTH and 25(OH)D levels were measured with the aid of a microparticle immunoassay system that detected chemiluminescence (ARCHITECT i2000; Abbott Diagnostics, Abbott Park, IL). In a comparative study of automated immunoassays and liquid chromatography-tandem mass spectrometry methods (LC-MS/MS) (23), the Abbott 25(OH)D assay was comparable to LC-MS/MS; the concordance correlation coefficient was 0.85 , and the mean bias was $4.56 \mathrm{ng} / \mathrm{mL}$. The coefficient of variation for the total analytic precision of the PTH assay was $9 \%$ and the lower detection limit was $1.0 \mathrm{pg} / \mathrm{mL}$. The coefficient of variation for the $25(\mathrm{OH}) \mathrm{D}$ assay was $10 \%$, and the lower detection limit was $3.0 \mathrm{ng} / \mathrm{mL}$.

Statistical analysis. We used IBM SPSS software 22.0 (IBM Corp., Armonk, NY) for the statistical analyses. Baseline demographics are presented as number and per cent or mean and standard deviation (SD) across levels of 25(OH)D. eGFR and ACR values were transformed to logarithmic values because eGFR and ACR did not show a normal distribution. The mean values of eGFR and ACR according to the $25(\mathrm{OH}) \mathrm{D}$ levels were compared by using analysis of covariance (ANCOVA) models. Sex, age, and the month of blood collection were adjusted in Model I. Health behavior variables, medication of antihypertension and anti-diabetes, multi-vitamin intake, lipid profile, parathyroid hormone, and the variables of Model I were adjusted in Model II. The log-transformed ACR or log-transformed eGFR and the variables of Model II were adjusted in Model III. As an additional analysis, we plotted the predicted Z-score of $25(\mathrm{OH}) \mathrm{D}$ with fractional polynomials with default settings in Stata version 11.0 (StataCorp, College Station, TX). We used as a cutoff for statistical significance a $p$-value less than 0.05.

\section{RESULTS}

\section{General characteristics across the 25(OH)D levels}

Table 1 shows the general characteristics across the 25(OH)D levels. Participants with increasing 25(OH)D levels were highly likely to be male, have a higher intake of alcohol, be more physically active, use less anti-diabetes medication, and have a lower intake of multivitamins and a lower percentage of albuminuria $(p<0.05)$. Height and weight tended to increase in participants with higher $25(\mathrm{OH}) \mathrm{D}$ levels $(p<0.001)$. By contrast, triglyceride, HDL-C, PTH, and ACR tended to decrease in participants with higher $25(\mathrm{OH}) \mathrm{D}$ levels $(p<0.001)$. 
Table 1. General characteristics across the 25(OH)D levels.

\begin{tabular}{|c|c|c|c|c|c|c|}
\hline \multirow{2}{*}{ Variables } & \multicolumn{4}{|c|}{$25(\mathrm{OH}) \mathrm{D}(\mathrm{ng} / \mathrm{mL})$} & \multirow{2}{*}{ Total } & \multirow{2}{*}{$p$} \\
\hline & $<10.0$ & $10.0-14.9$ & $15.0-19.9$ & $\geq 20.0$ & & \\
\hline$n(\%)$ & $725(7.91)$ & $3,326(36.29)$ & $2,908(31.73)$ & $2,207(24.08)$ & $9,166(100.0)$ & \\
\hline Male (\%) & $104(14.3)$ & $779(23.4)$ & $1,321(45.43)$ & $1,464(66.33)$ & $3,668(40.02)$ & $<0.001$ \\
\hline Age (y) & $66.6 \pm 8.47$ & $65.2 \pm 8.33$ & $64.7 \pm 8.02$ & $65.1 \pm 7.95$ & $65.2 \pm 8.17$ & $<0.001$ \\
\hline Month of blood collection & & & & & & $<0.001$ \\
\hline March & $11(1.5)$ & $52(1.6)$ & $21(0.7)$ & $6(0)$ & $90(1.0)$ & \\
\hline April & $236(32.6)$ & $754(22.7)$ & $500(17.2)$ & $267(12.1)$ & $1,757(19.17)$ & \\
\hline May & $291(40.1)$ & $1,207(36.29)$ & $902(31.0)$ & $599(27.1)$ & $2,999(32.72)$ & \\
\hline June & $132(18.2)$ & $888(26.7)$ & $924(31.8)$ & $793(35.9)$ & $2,737(29.86)$ & \\
\hline July & $55(7.6)$ & $425(12.8)$ & $561(19.3)$ & $542(24.6)$ & $1,583(17.27)$ & \\
\hline Height $(\mathrm{cm})$ & $154 \pm 7.50$ & $156 \pm 7.70$ & $159 \pm 8.34$ & $162 \pm 8.20$ & $158 \pm 8.39$ & $<0.001$ \\
\hline Weight (kg) & $57.3 \pm 8.61$ & $59.7 \pm 8.97$ & $62.1 \pm 9.45$ & $63.1 \pm 9.27$ & $61.1 \pm 9.33$ & $<0.001$ \\
\hline BMI $\left(\mathrm{kg} / \mathrm{m}^{2}\right)$ & $24.2 \pm 3.12$ & $24.5 \pm 3.03$ & $24.4 \pm 2.92$ & $24.1 \pm 2.70$ & $24.4 \pm 2.93$ & $<0.001$ \\
\hline Waist circumference $(\mathrm{cm})$ & $154 \pm 7.50$ & $156 \pm 7.70$ & $159 \pm 8.34$ & $162 \pm 8.20$ & $158.3 \pm 8.39$ & $<0.001$ \\
\hline Smoking (\%) & $61(8.4)$ & $265(7.98)$ & $344(11.8)$ & $326(14.8)$ & $996(10.9)$ & $<0.001$ \\
\hline Alcohol intake (\%) & $188(26.1)$ & $1,236(37.25)$ & $1,486(51.26)$ & $1,307(59.36)$ & $4,217(46.14)$ & $<0.001$ \\
\hline Physically active $^{1}(\%)$ & $389(53.7)$ & $2,014(60.55)$ & $1,885(64.82)$ & $1,517(68.74)$ & $5,805(63.33)$ & $<0.001$ \\
\hline Anti-hypertensive medication (\%) & $266(37.4)$ & $1,168(35.33)$ & $1,069(36.99)$ & $733(33.4)$ & $3,236(35.55)$ & 0.04 \\
\hline Anti-diabetes medication (\%) & $101(14.2)$ & $444(13.4)$ & $384(13.3)$ & $244(11.1)$ & $1,173(12.90)$ & 0.04 \\
\hline Multi-vitamin intake (\%) & $558(80.9)$ & $2,535(78.48)$ & $2,187(77.55)$ & $1,548(71.87)$ & $6,828(76.77)$ & $<0.001$ \\
\hline Total cholesterol (mg/dL) & $217 \pm 44.5$ & $207.8 \pm 40.07$ & $196.9 \pm 37.76$ & $191.6 \pm 37.91$ & $201.2 \pm 40.03$ & $<0.001$ \\
\hline Triglycerides (mg/dL) & $161 \pm 154$ & $146.3 \pm 97.18$ & $139.4 \pm 90.95$ & $136.9 \pm 94.13$ & $143.0 \pm 100.5$ & $<0.001$ \\
\hline HDL cholesterol (mg/dL) & $53.7 \pm 12.5$ & $52.36 \pm 11.91$ & $50.92 \pm 11.86$ & $50.48 \pm 11.89$ & $51.56 \pm 11.98$ & $<0.001$ \\
\hline PTH (pg/mL) & $53.2 \pm 31.7$ & $46.03 \pm 24.26$ & $41.33 \pm 17.55$ & $38.14 \pm 15.21$ & $43.20 \pm 21.55$ & $<0.001$ \\
\hline eGFR $\left(\mathrm{mL} / \mathrm{min} / 1.73 \mathrm{~m}^{2}\right)$ & $69.0 \pm 15.0$ & $69.45 \pm 13.95$ & $69.09 \pm 13.48$ & $68.35 \pm 13.31$ & $69.04 \pm 13.74$ & 0.04 \\
\hline CKD $\left(\%\right.$, eGFR $\left.<60 \mathrm{~mL} / \mathrm{min} / 1.73 \mathrm{~m}^{2}\right)$ & $174(24.0)$ & $780(23.4)$ & $677(23.3)$ & $555(25.1)$ & $2,186(23.84)$ & 0.41 \\
\hline ACR $(\mu \mathrm{g} / \mathrm{mg}$ creatinine $)$ & $60.1 \pm 230$ & $40.85 \pm 132.0$ & $33.52 \pm 94.04$ & $32.96 \pm 91.17$ & $38.15 \pm 123.9$ & $<0.001$ \\
\hline $\begin{array}{l}\text { Albuminuria } \\
\text { (\%, ACR }>30 \mu \mathrm{g} / \mathrm{mg} \text { creatinine) }\end{array}$ & $174(24.0)$ & $704(21.2)$ & $571(19.7)$ & $418(19.0)$ & $1,867(20.39)$ & 0.01 \\
\hline
\end{tabular}

All values are given as $n(\%)$ or mean \pm standard deviation.

25(OH)D, 25-hydroxyvitamin D; BMI, body mass index; HDL, high-density lipoprotein; PTH, parathyroid hormone; eGFR, estimated glomerular filtration rate; CKD, chronic kidney disease; ACR, albumin creatinine ratio.

${ }^{1}$ Subjects who performed $30 \mathrm{~min}$ or more of walking at least $5 \mathrm{~d}$ a week.

Table 2. ANCOVA analysis of the mean eGFR and ACR values across the 25(OH)D levels.

\begin{tabular}{lcccc}
\hline \multicolumn{1}{c}{ Variables } & 25(OH)D levels & $\begin{array}{c}\text { Model 1 } \\
\text { Mean }(95 \% \mathrm{CI})\end{array}$ & $\begin{array}{c}\text { Model 2 } \\
\text { Mean }(95 \% \mathrm{CI})\end{array}$ & $\begin{array}{c}\text { Model 3 } \\
\text { Mean }(95 \% \mathrm{CI})\end{array}$ \\
\hline eGFR & $<10.0$ & $70.5(69.5-71.4)$ & $71.5(70.6-72.5)$ & $71.5(70.5-72.4)$ \\
$\left(\mathrm{mL} / \mathrm{min} / 1.73 \mathrm{~m}^{2}\right)$ & $10.0-14.9$ & $69.6(69.2-70.1)$ & $70.0(69.6-70.4)$ & $70.0(69.5-70.4)$ \\
& $15.0-19.9$ & $68.7(68.3-69.2)$ & $68.7(68.3-69.2)$ & $68.7(68.3-69.2)$ \\
& $\geq 20.0$ & $68.1(67.5-68.6)$ & $67.4(66.9-68.0)$ & $67.4(66.8-67.9)$ \\
& $p$ value & $<0.001$ & $<0.001$ & $<0.001$ \\
ACR & $<10.0$ & $59.2(50.0-68.4)$ & $53.9(44.3-63.5)$ & $57.4(48.0-66.9)$ \\
$(\mu \mathrm{g} / \mathrm{mg}$ creatinine $)$ & $10.0-14.9$ & $41.6(37.2-45.9)$ & $39.2(34.8-43.7)$ & $40.8(36.5-45.2)$ \\
& $15.0-19.9$ & $33.8(29.3-38.3)$ & $34.5(29.9-39.1)$ & $34.0(29.5-38.5)$ \\
& $\geq 20.0$ & $31.9(26.4-37.3)$ & $37.2(31.6-42.7)$ & $34.3(28.8-39.8)$ \\
& $p$ value & $<0.001$ & 0.01 & $<0.001$
\end{tabular}

Model 1, Adjusted by month of blood collection, sex and age.

Model 2, Adjusted by Model 1 plus waist circumference, smoking, alcohol intake, physical activity, anti-hypertension medications, anti-diabetes medication, multi-vitamin intake, total cholesterol, triglyceride, HDL cholesterol, and PTH.

Model 3, Adjusted by Model 2 plus log-transformed ACR or log-transformed eGFR. 


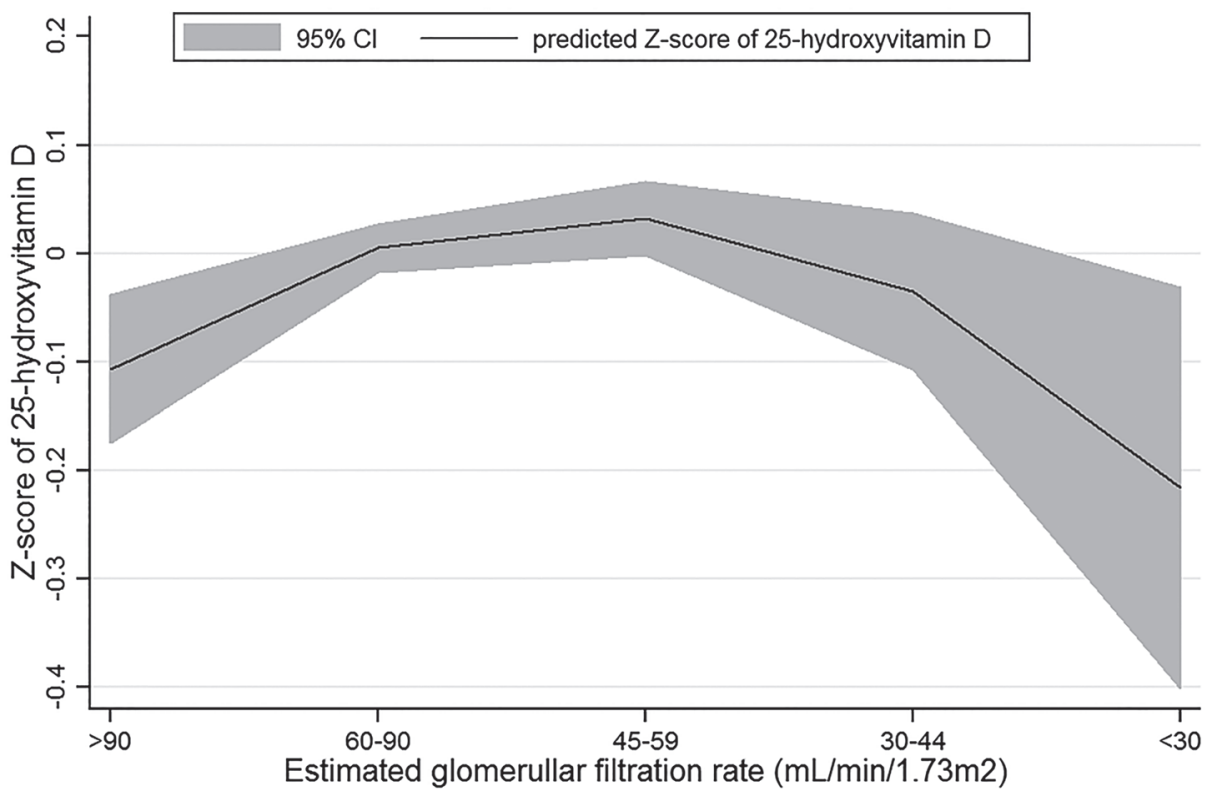

Fig. 1. Distribution of the Z-score of 25(OH)D cross the eGFR levels.

ANCOVA analysis of the mean eGFR and ACR values across the 25(OH)D levels

Table 2 shows ANCOVA analysis of the mean values (95\% confidence interval [CI]) of eGFR and ACR across the $25(\mathrm{OH}) \mathrm{D}$ levels. When adjusted with covariates (sex, age, month of blood collection, health behavior variables, medication for anti-hypertension and antidiabetes, multivitamin intake, lipid profile, parathyroid hormone) and log-transformed ACR (Model III), lower eGFR values were significantly associated with increasing 25(OH)D levels $(<10.0$ : 71.5 [70.5-72.4]; 10.014.9: 70.0 [69.5-70.4]; 15.0-19.9: 68.7 [68.3-69.2]; $\geq 20.0: 67.4$ [66.8-67.9] $\left.\mathrm{mL} / \mathrm{min} / 1.73 \mathrm{~m}^{2}, p<0.001\right)$. When adjusted for the same covariates and log-transformed eGFR (Model III), the lower ACR values were significantly associated with increasing $25(\mathrm{OH}) \mathrm{D}$ levels $(<10.0$ : 57.4 [48.0-66.9]; 10.0-14.9: 40.8 [36.545.2]; 15.0-19.9: 34.0 [29.5-38.5]; $\geq 20.0: 34.3$ [28.8-39.8] $\mu \mathrm{g} / \mathrm{mg}$ creatinine, $p<0.001)$.

Distribution of the Z-score of 25(OH)D across the eGFR levels

Figure 1 shows the distribution of the Z-score of $25(\mathrm{OH}) \mathrm{D}$ across the eGFR levels. The Z-score of $25(\mathrm{OH}) \mathrm{D}$ was at its highest level at eGFR $45-59 \mathrm{~mL} / \mathrm{min} / 1.73$ $\mathrm{m}^{2}$. In addition, when the eGFR was lower than $45-59 \mathrm{~mL} / \mathrm{min} / 1.73 \mathrm{~m}^{2}$, the $\mathrm{Z}$ score of $25(\mathrm{OH}) \mathrm{D}$ was reduced with decreasing levels of eGFR.

\section{DISCUSSION}

We estimated the relationship among ACR, eGFR, and $25(\mathrm{OH}) \mathrm{D}$ with subjects aged $\geq 50 \mathrm{y}$ in Korea. Our results demonstrated that the lower eGFR and ACR values were significantly associated with higher 25(OH)D levels in subjects aged $\geq 50 \mathrm{y}$ in Korea.

In our study, when adjusted for covariates, the lower eGFR values were significantly associated with increasing levels of 25(OH)D. Previous researchers have inves- tigated the relationship of $25(\mathrm{OH}) \mathrm{D}$ with eGFR, but results have been inconsistent (11-16). The exact reasons for these discrepancies are unknown, but there are some explanations. First, the prevalence of severe renal impairments might affect the relationship; studies of CKD patients identified a positive association between the eGFR and vitamin D levels $(12,24)$, while those without CKD patients found a negative association (14, 25). Second, the association between eGFR and vitamin $\mathrm{D}$ varied according to the eGFR and $25(\mathrm{OH}) \mathrm{D}$ concentrations of the participants $(11,26)$. Recently, a negative association between eGFR and 25(OH)D has been reported in a Korean people known as a vitamin D deficient population. In the survey with 11,336 Korean subjects, 25(OH)D was negatively correlated with eGFR (13). Furthermore, in the cross-sectional study with 1,648 Korean adults, the elevated eGFR concentrations were highly correlated with reduced $25(\mathrm{OH}) \mathrm{D}$ level (14).

It was unexpected that $25(\mathrm{OH}) \mathrm{D}$ was inversely correlated with eGFR; previous studies have indicated that $25(\mathrm{OH}) \mathrm{D}$ has renoprotective effects $(27)$. However, various mechanisms may underlie this negative association between the eGFR and the 25(OH)D. Because the hydroxylation of $25(\mathrm{OH}) \mathrm{D}$ to the biologically active metabolite occurs within the kidneys, renal deficiency results in reduced $1,25(\mathrm{OH})_{2} \mathrm{D}$ concentrations due to the stagnating metabolism of $25(\mathrm{OH}) \mathrm{D}(28)$. In addition, impaired metabolism may be mediated by the activity of fibroblast growth factor 23, which suppresses the hydroxylation of $25(\mathrm{OH}) \mathrm{D}$ and encourages the catabolism of $1,25(\mathrm{OH})_{2} \mathrm{D}(29)$. Thus, it is plausible that $25(\mathrm{OH}) \mathrm{D}$ concentrations are higher in the initial stages of CKD than in the normal eGFR (28). A previous study with KNHANES 2011-2012 (13) reported that the highest $25(\mathrm{OH}) \mathrm{D}$ values occurred at the level of eGFR $61-90 \mathrm{~mL} / \mathrm{min} / 1.73 \mathrm{~m}^{2}$. However, our result showed that the mean $25(\mathrm{OH}) \mathrm{D}$ value was at its highest 
level at eGFR $45-59 \mathrm{~mL} / \mathrm{min} / 1.73 \mathrm{~m}^{2}$. The gap in the eGFR level at which $25(\mathrm{OH}) \mathrm{D}$ was highest may be due to the difference in the population age (previous study:

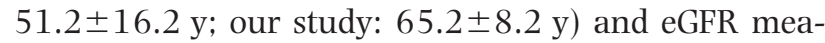
surement (previous study: MDRD equation; our study: CKD-EPI equation).

In our study, after being adjusted for covariates, the reduced ACR value was significantly correlated with the elevated quartile of $25(\mathrm{OH}) \mathrm{D}$. A cross-sectional study with 15,068 in the United States demonstrated that the decreased $25(\mathrm{OH}) \mathrm{D}$ levels were highly related to the prevalence of albuminuria (30). In a previous KNHANES 2012 study with 4,948 subjects (31), vitamin D deficiency was significantly associated with an elevated ACR level, similar to our result. The correlation between albuminuria and $25(\mathrm{OH}) \mathrm{D}$ levels is well established (32). First, the renin-angiotensin system (33) and nuclear factor- $\kappa \mathrm{B}(\mathrm{NF}-\kappa \mathrm{B})$ pathway might be inhibited by vitamin D (34). Second, vitamin D directly affects cell proliferation, differentiation, and apoptosis $(35,36)$. Moreover, the relation of vitamin D with kidney function seems to be bidirectional because it appears that renal dysfunction might lead to decreases in vitamin $\mathrm{D}$ levels. Vitamin D is reabsorbed in the proximal tubule via the actions of megalin and cubilin (37); thus, it is also possible that the increased filtration of albumin into the urinary space interferes with vitamin D reabsorption, which, in turn, leads to greater losses of vitamin $\mathrm{D}$ via the urine.

A relatively large sample size and the populationbased design are strengths of our study. However, there are certain limitations. First, because of the cross-sectional design, we were unable to examine the causal relationships among 25(OH)D, eGFR and ACR. Second, because our study participants had very low levels of vitamin $\mathrm{D}$, the outcomes could be affected by a skewed distribution of vitamin D. However, KNHANES data, which is representative of Koreans (38), showed similar low levels of vitamin D. In the study with KNHANES data, 38\% subjects exhibited less than $15.0 \mathrm{ng} / \mathrm{mL}$ (31) and $75 \%$ subjects less than $20.5 \mathrm{ng} / \mathrm{mL}$ (13). Third, information on sunlight exposure and dietary vitamin D intake was not examined. But instead, we have investigated "multi-vitamin intake" and "physical activity", which presumably reflect sunlight exposure and dietary vitamin D intake. Finally, we estimated GFR using the equation for CKD-EPI for improving the imprecision and bias. However, because the CKD-EPI equation was developed based on serum creatinine, it is influenced by muscle mass, dietary food, and secretion in renal tubules (39).

In conclusion, the mean values of eGFR were significantly decreased with increasing $25(\mathrm{OH}) \mathrm{D}$ levels independent of ACR. Moreover, the mean values of ACR were significantly decreased with increasing $25(\mathrm{OH}) \mathrm{D}$ levels independent of eGFR in participants aged $\geq 50 \mathrm{y}$ in Korea.

\section{Acknowledgments}

We would like to thank all who participated in the
Dong-gu Study.

\section{REFERENCES}

1) Collins AJ, Foley RN, Chavers B, Gilbertson D, Herzog C, Johansen K, Kasiske B, Kutner N, Liu J, St Peter W, Guo H, Gustafson S, Heubner B, Lamb K, Li S, Li S, Peng Y, Qiu Y, Roberts T, Skeans M, Snyder J, Solid C, Thompson B, Wang C, Weinhandl E, Zaun D, Arko C, Chen SC, Daniels F, Ebben J, Frazier E, Hanzlik C, Johnson R, Sheets D, Wang X, Forrest B, Constantini E, Everson S, Eggers P, Agodoa L. 2012. US renal data system 2011 annual data report. Am J Kidney Dis 59: A7.

2) Gansevoort RT, Correa-Rotter R, Hemmelgarn BR, Jafar TH, Heerspink HJL, Mann JF, Matsushita K, Wen CP. 2013. Chronic kidney disease and cardiovascular risk: epidemiology, mechanisms, and prevention. Lancet 382: 339-352.

3) Bernaudo D, Coll R, Sánchez Muñoz-Torrero JF, Pascual MT, García-Díaz AM, Álvarez LR, Monreal M. 2013. Renal function and short-term outcome in stable outpatients with coronary, cerebrovascular or peripheral artery disease. Atherosclerosis 229: 258-262.

4) Eisen A, Porter A, Hoshen M, Balicer RD, Reges O, Rabi Y, Leibowitz M, Iakobishvili Z, Hasdai D. 2018. The association between eGFR in the normal or mildly impaired range and incident cadiovascular disease: Age and sex analysis. Eur J Intern Med 54: 70-75.

5) Ninomiya T, Perkovic V, de Galan BE, Zoungas S, Pillai A, Jardine M, Patel A, Cass A, Neal B, Poulter N, Mogensen CE, Cooper M, Marre M, Williams B, Hamet P, Mancia G, Woodward M, Macmahon S, Chalmers J, Group AC. 2009. Albuminuria and kidney function independently predict cardiovascular and renal outcomes in diabetes. J Am Soc Nephrol 20: 1813-1821.

6) Gerstein HC, Mann JF, Yi Q, Zinman B, Dinneen SF, Hoogwerf B, Hallé JP, Young J, Rashkow A, Joyce C, Nawaz S, Yusuf S; HOPE Study Investigators. 2001. Albuminuria and risk of cardiovascular events, death, and heart failure in diabetic and nondiabetic individuals. JAMA 286: 421-426.

7) Goolsby MJ. 2002. National kidney foundation guidelines for chronic kidney disease: evaluation, classification, and stratification. J Am Acad Nurse Pract 14: 238-242.

8) Holick MF. 1996. Vitamin D and bone health. J Nutr 126: 1159 S-1164S.

9) Holick MF. 1999. Evolution, biologic functions, and recommended dietary allowances for vitamin D. In: Vitamin D (Holick MF ed), p 1-16. Humana Press, Totowa, NJ.

10) Inouye K, Sakaki T. 2001. Enzymatic studies on the key enzymes of vitamin D metabolism; 1 alpha-hydroxylase (CYP27B1) and 24-hydroxylase (CYP24). Biotechnol Апnu Rev 7: 179-194.

11) Oh YJ, Kim M, Lee H, Lee JP, Kim H, Kim S, Oh KH, Joo KW, Lim CS, Kim S, Kim YS, Kim DK. 2012. A threshold value of estimated glomerular filtration rate that predicts changes in serum 25-hydroxyvitamin D levels: 4th Korean National Health and Nutritional Examination Survey 2008. Nephrol Dial Transplant 27: 2396-2403.

12) Patel S, Barron JL, Mirzazedeh M, Gallagher H, Hyer S, Cantor T, Fraser WD. 2011. Changes in bone mineral parameters, vitamin D metabolites, and PTH measurements with varying chronic kidney disease stages. J Bone Miner Metab 29: 71-79.

13) Park J, Ryu SY, Han MA, Choi SW. 2016. The associa- 
tion of vitamin D with estimated glomerular filtration rate and albuminuria: 5th Korean National Health and Nutritional Examination Survey 2011-2012. J Ren Nutr 26: 360-366.

14) Tak YJ, Lee JG, Song SH, Kim YJ, Lee S, Jung DW, Yi YH, Cho YH, Choi EJ, Hwang HR. 2015. The relationship between the level of serum 25-hydroxyvitamin D and renal function in patients without chronic kidney disease: a cross-sectional study. J Ren Nutr 25: 88-96.

15) Wang WH, Chen LW, Lee CC, Sun CY, Shyu YC, Hsu HR, Chien RN, Wu IW. 2017. Association between parathyroid hormone, $25(\mathrm{OH})$ vitamin $\mathrm{D}$, and chronic kidney disease: a population-based study. Biomed Res Int 2017: 7435657.

16) Guessous I, McClellan W, Kleinbaum D, Vaccarino V, Zoller O, Theler JM, Paccaud F, Burnier M, Bochud M; Swiss Survey on Salt Group. 2014. Comparisons of serum vitamin D levels, status, and determinants in populations with and without chronic kidney disease not requiring renal dialysis: a 24-hour urine collection population-based study. J Ren Nutr 24: 303-312.

17) Lips P. 2010. Worldwide status of vitamin D nutrition. J Steroid Biochem Mol Biol 121: 297-300.

18) Lips P, Hosking D, Lippuner K, Norquist JM, Wehren L, Maalouf G, Ragi-Eis S, Chandler J. 2006. The prevalence of vitamin D inadequacy amongst women with osteoporosis: an international epidemiological investigation. $J$ Intern Med 260: 245-254.

19) Kweon SS, Shin MH, Jeong SK, Nam HS, Lee YH, Park KS, Ryu SY, Choi SW, Kim BH, Rhee JA, Zheng W, Choi JS. 2014. Cohort profile: The Namwon Study and the Dong-gu Study. Int J Epidemiol 43: 558-567.

20) Saha H. 1994. Calcium and vitamin D homeostasis in patients with heavy proteinuria. Clin Nephrol 41: 290-296.

21) Levey AS, Stevens LA, Schmid CH, Zhang YL, Castro AF, Feldman HI, Kusek JW, Eggers P, Van Lente F, Greene T, Coresh J; CKD-EPI. 2009. A new equation to estimate glomerular filtration rate. Ann Intern Med 150: 604-612.

22) Lustgarten JA, Wenk RE. 1972. Simple, rapid, kinetic method for serum creatinine measurement. Clin Chem 18: 1419-1422.

23) Farrell CJL, Martin S, McWhinney B, Straub I, Williams P, Herrmann M. 2012. State-of-the-art vitamin D assays: a comparison of automated immunoassays with liquid chromatography-tandem mass spectrometry methods. Clin Chem 58: 531-542.

24) Ravani P, Malberti F, Tripepi G, Pecchini P, Cutrupi S, Pizzini P, Mallamaci F, Zoccali C. 2009. Vitamin D levels and patient outcome in chronic kidney disease. Kidney Int 75: 88-95.

25) Karhapää P, Pihlajamäki J, Pörsti I, Kastarinen M, Mustonen J, Niemelä O, Tuomi H, Kuusisto J. 2012. Glomerular filtration rate and parathyroid hormone are asso- ciated with 1,25-dihydroxyvitamin D in men without chronic kidney disease. J Intern Med 271: 573-580.

26) O'Seaghdha CM, Hwang S-J, Holden R, Booth SL, Fox CS. 2012. Phylloquinone and vitamin D status: associations with incident chronic kidney disease in the Framingham Offspring cohort. Am J Nephrol 36: 68-77.

27) Li YC. 2012. Vitamin D: roles in renal and cardiovascular protection. Curr Opin Nephrol Hypertens 21: 72-79.

28) Bosworth CR, Levin G, Robinson-Cohen C, Hoofnagle AN, Ruzinski J, Young B, Schwartz SM, Himmelfarb J, Kestenbaum B, de Boer IH. 2012. The serum 24,25-dihydroxyvitamin D concentration, a marker of vitamin D catabolism, is reduced in chronic kidney disease. Kidney Int 82: 693-700.

29) Quarles LD. 2012. Role of FGF23 in vitamin D and phosphate metabolism: Implications in chronic kidney disease. Exp Cell Res 318: 1040-1048.

30) de Boer IH, Ioannou GN, Kestenbaum B, Brunzell JD, Weiss NS. 2007. 25-Hydroxyvitamin D levels and albuminuria in the third National Health and Nutrition Examination Survey (NHANES III). Am J Kidney Dis 50: 69-77.

31) Kim SG, Kim GS, Lee JH, Moon AE, Yoon H. 2018. The relationship between vitamin $\mathrm{D}$ and estimated glomerular filtration rate and urine microalbumin/creatinine ratio in Korean adults. J Clin Biochem Nutr 62: 94-99.

32) Damasiewicz MJ, Magliano DJ, Daly RM, Gagnon C, Lu ZX, Ebeling PR, Chadban SJ, Atkins RC, Kerr PG, Shaw JE, Polkinghorne KR. 2012. 25-Hydroxyvitamin D levels and chronic kidney disease in the AusDiab (Australian Diabetes, Obesity and Lifestyle) study. BMC Nephrol 13: 55.

33) Li YC, Qiao G, Uskokovic M, Xiang W, Zheng W, Kong J. 2004. Vitamin D: a negative endocrine regulator of the renin-angiotensin system and blood pressure. I Steroid Biochem Mol Biol 89-90: 387-392.

34) Sun J, Kong J, Duan Y, Szeto FL, Liao A, Madara JL, Li YC. 2006. Increased NF- $\kappa$ B activity in fibroblasts lacking the vitamin D receptor. Am J Physiol Endocrinol Metab 291: E315-E322.

35) Masuda S, Jones G. 2006. Promise of vitamin D analogues in the treatment of hyperproliferative conditions. Mol Cancer Ther 5: 797-808.

36) Dusso AS, Brown AJ, Slatopolsky E. 2005. Vitamin D. Am J Physiol Renal Physiol 289: F8-F28.

37) Christensen EI, Birn H. 2001. Megalin and cubilin: synergistic endocytic receptors in renal proximal tubule. Am J Physiol Renal Physiol 280: F562-F573.

38) Kweon S, Kim Y, Jang Mj, Kim Y, Kim K, Choi S, Chun C, Khang YH, Oh K. 2014. Data resource profile: the Korea National Health and Nutrition Examination Survey (KNHANES). Int J Epidemiol 43: 69-77.

39) Stevens LA, Coresh J, Greene T, Levey AS. 2006. Assessing kidney function-measured and estimated glomerular filtration rate. N Engl J Med 354: 2473-2483. 